\title{
Is Radiocarbon a “Tracer” for Long Period Solar Variability?
}

\author{
Charles P. SONETT \\ Dept. of Planetary Sciences and Lunar and Planetary Laboratory, \\ University of Arizona, Tucson, Arizona 85721, U.S.A.
}

(Received August 24, 1990; Revised November 20, 1990)

The inventory of atmospheric radiocarbon exhibits quasi-periodic variations over its entire 9000 year record with major periods at $\bar{\Lambda}_{m} \sim=200$ and $\bar{\Lambda}_{c} \sim 2300$ years. Both periods are inconstant and subject to random variability (For the 200 year period the large standard deviation, $\sigma_{m}{ }^{1 / 2} \sim 129$ years, relative to the mean suggests a signiflcant noise contribution to this period). This $\sim 200$ year period marks maxima in the radiocarbon inventory and suggests a correspondence with an extension of the Maunder minimum throughout the Holocene and suggests resolution of the long-standing issue of Maunder cyclicity. The radiocarbon maxima are amplitude modulated by the $\sim 2300$ year period and thus vary significantly in peak value. Detection of a Maunder-like sequence of minima in tree ring growth of Bristlecone pine and its correlation with the Maunder-like cyclicity in the radiocarbon record supports the inference that solar forcing of the radiocarbon record is accompanied by a corresponding forcing of growth of timberline Bristlecone pine. Because of the quasi-random character of the Maunder period, prediction of climate if tied to the Maunder cycle, other than probabilistically, is significantly hindered. The probability appears to be about $67 \%$ that a given climatic maximum lies anywhere between 80 and 338 years.

\section{The Delta Radiocarbon Sequence}

The radiocarbon sequence reported upon here is composed of segments, sometimes overlapping, from records from PEARSON et al. (1986), LINICK et al. (1986), KROMER et al. (1986), and SUESS (1980). To make up a continuous sequence we interleaved all records in ascending time. The composite time sequence is shown in Fig. 1. This composite sequence extends from $7202 \mathrm{BC}-1900 \mathrm{AD}$. As some data are not evenly spaced, we derived a uniformly spaced sequence (10 year intervals) using a polynomial (dark line in Fig. 1) detrend function. The major trend is generally attributed to a nearly secular increase in the Earth's magnetic field (BUCHTA, 1970; BARTON et al., 1979; McELHINNEY and SENENYAKE, 1982; CREER, 1988) (and has often been removed using a sinusoidal function). The filtered, splined, and equally spaced $\Delta^{14} \mathrm{C}$ sequence contains the complete spectrum of variations, including a very long period component identified as the $\Lambda_{c} \sim 2300$ year line. The numerical filter uses a set of nine Pascal distributed weights, 1, 2, 3, 4, 5, 4, 3, 2, and 1 (filtering to 100 years). This is followed by subtraction of a low frequency version obtained by passing the sequence through 99 Pascal weights with cutoff $\sim 1000$ years. This yields the multi-hundred year response sequence which displays 34 maxima of varying amplitude in the 100-1000 year period band. The narrow-banded sequence is shown in Fig. 2. This figure should be regarded 


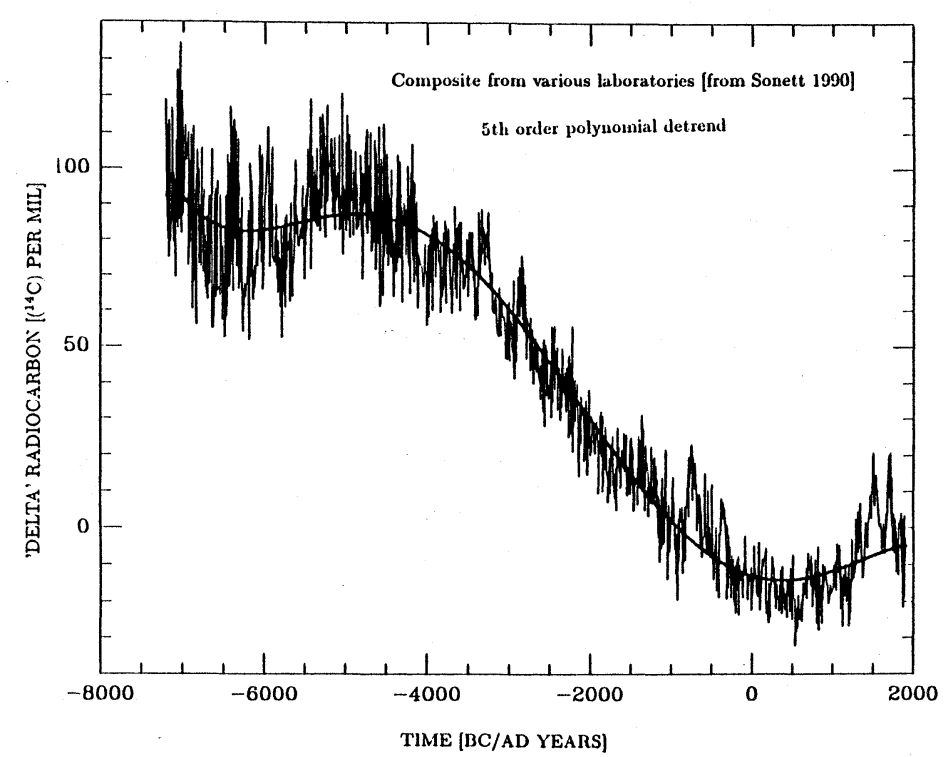

Fig. 1. Composite delta radiocarbon record showing variability on several scales. The longest ('secular') variation is attributed primarily to changes in the geomagnetic field. Other significant variations are the 2300 and 200 year signals, both noted in this record. The heavy line is the 5 th order polynomial used to remove the long trend.

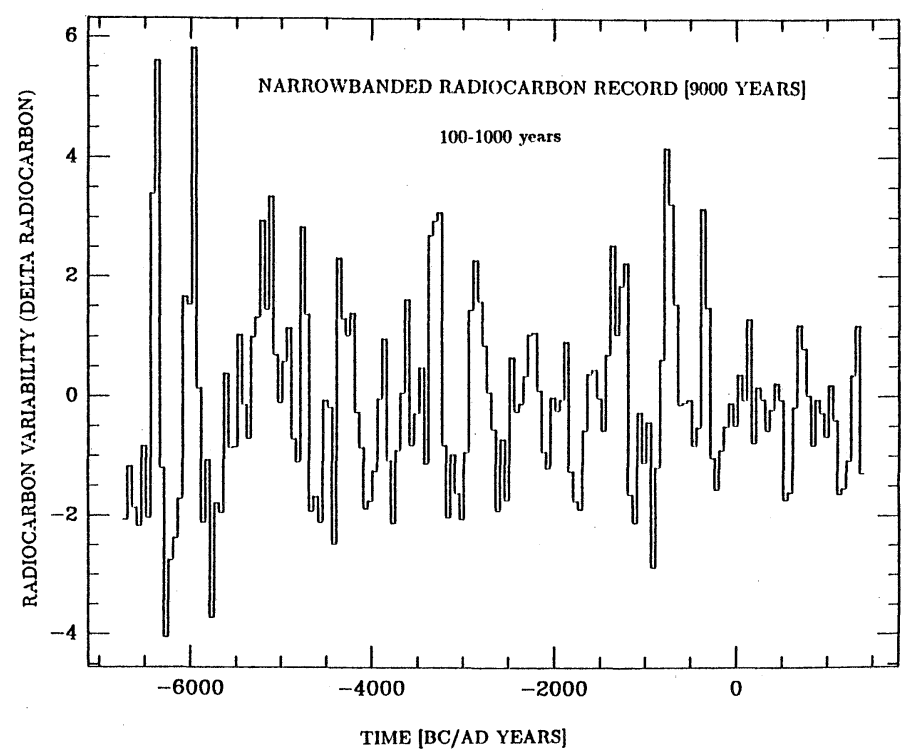

Fig. 2. $\Delta^{14} \mathrm{C}$ narrow banded to emphasize the dominant period characterized by $\Lambda_{m}=209$ years. 2300 year variability can be seen as an amplitude modulation of the sequence peaks with vestigial suggestion of $\sim 1000$ year period. Decimation on 10 year centers. 
as qualitative until such time as more specific and quantitative criteria can be expressed for threshold assumed for the statistics governing the transition in amplitude from noise to signal + noise. The complication inferred by these comments is based upon the very large variance. Assuming this represents the second moment of normally distributed noise, then putative Maunder cycles have a $67 \%$ chance of lying between anywhere between 80 and 338 years. If a climatic correlation can be shown to exist with Maunder minima (hardly certain but plausible) then long term climate can hardly be regarded as an easily predictable parameter.

The more recent maxima suggest a qualitative similarity with the last millenium results for solar activity (Maunder) minima (STUIVER and QUAY, 1981). The largest scale variability in amplitude appears to be explained by the finding of SONETT (1985) that the 2300 year forcing amplitude modulates the 200 year period. Thus maxima during the last millennium are much smaller than earlier. However the narrow banding is a risky proceedure since even narrow banded white noise takes on the appearance of a sinusoid. This not alway recognized result of filtering corresponds to the classical noise model of Uhlenbeck and Goudsmit of many years ago wherein white noise can be modelled by an infinite set of random phase oscillators of ajoining frequency and Gaussian amplitude. In the present filtered version of the delta radiocarbon sequence we have not attempted to analytically distinguish between noise and signal.

Stuiver and Brasiunis have analysed a version of the radiocarbon sequence filtered using a 400 year running average. Such a filter has its first zero at a period of 400 years and a half power point at 900 years. Thus shorter periods are attenuated increasingly with frequency. They report three regions of enhanced delta radiocarbon response. These regions appear to correspond to the strong modulation of the 208 year period by a 2300 year period reported by SONETT (1985) and SONETT and FINNEY (1990).

It is tempting to regard the filtered signal as representations of Maunder-like minima, i.e. defined as a period of vanishing sunspot activity, i.e. zero or very small. But then earlier and larger minima (corresponding to radiocarbon maxima) must be explained by either a fictitius negative sunspot index or, what seems more likely, that the 200 year period has an intrinsic range far greater than seen in the Maunder cycle. Both STUIVER and BRAZIUNAS (1989) and SONETT (in press) have regarded the filtered data as Maunder-like but aside from the aforementioned problem, it should be noted that the frequency variance is approximately half the mean frequency. It is presumably because of this that identified with a specific line in the spectrum is controversial. We cannot rule out the possibility that in the filtering we have reached deep into the intrinsic noise. It is nevertheless true that the semblance of modulation and the reality of the 3-4 Maunder-like periods in the last millenium infer that at least part of the filtered data contains coherent information.

Based upon the evidence of modulation from narrow banding as well as inspection of the time series, the apparent cyclicity appears to represents a highly modulated sequence with envelope maxima shown in Fig. 2 at 6500 BC, 5200 BC, 3300 BC, and 800 BC, which very crudely are suggestive of noisy maxima in the 2300 year response. Such a variability is difflcult to explain as due to extraterrestrial forcing. Indeed these times correspond very approximately to return times for global deep water though by itself this cannot explain the need for a real resonance. The problem reveals deeper complexity when it is recognized that assigning the 200 year period to extraterrestrial forcing (solar wind) is fundamentally a radiocarbon isotope problem (though secondary terrestrial geochemical effects may exist), 
while the longer period, if terrestrial, is a geochemical carbon dioxide effect for which radiocarbon assumes principally the role of a tracer.

\section{Bristlecone Pine Sequence}

The Campito Mt. Bristlecone record (3435 BC-1970) (LA MARCHE and HARLAN, 1973) from timberline in the White Mts. provides an absolute chronology of growth ring spacing (LA MARCHE and HARLAN, 1973; LA MARCHE, 1974). This sequence shows the same general properties as $\Delta^{14} \mathrm{C}$ but with maxima and minima opposed in phase with respect to the $\Delta^{14} \mathrm{C}$ record (SONETT and SUESS, 1984). The Bristlecone growth is forced solely by atmospheric temperature because of the extreme altitude and aridity. In turn it is reasonable to conclude that air temperature is positively correlated with solar irradiance. Although to evidence linking tree growth to solar irradiance is plausible, it is by no means certain that a more complex sequence of relations involving perhaps solar UV-photosynthesis or some other equally arcane forcing may lie at the root of the growth evidence.

The most parsimonous view is that of the air temperature relation. It implies that the presumably hydromagnetically forced cosmic ray variability underlying the radiocarbon variability is linked at the Sun to a variability in irradiance. The uncertain but suggestive evidence from the relative phases of the growth and radiocarbon records shows a negative correlation between radiocarbon and growth. Thus irradiance increases with solar activity, tending to modulate cosmic rays downwards.

\section{The Very Long Radiocarbon Period}

Both ${ }^{10} \mathrm{Be}$ and ${ }^{14} \mathrm{C}$ are produced by the $\mathrm{CR}$ flux, though production of ${ }^{10} \mathrm{Be}$ is via atmospheric spallations and is scavenged from the atmosphere in 2-3 years by attachment to aerosols (RAISBECK et al., 1981. Since production of ${ }^{14} \mathrm{C}$ and ${ }^{10} \mathrm{Be}$ are coeval and ${ }^{10} \mathrm{Be}$ is rapidly stored it serves as an important CR proxy to radiocarbon. ${ }^{10} \mathrm{Be}$ exhibits $9-11.4$ year variations as well as variability during the Maunder minimum. The Camp Century/Dome $\mathrm{C}$ composite ${ }^{10} \mathrm{Be}$ ice core record shows a remarkable though imperfect correlation inferring that the Maunder cycle is also present in the Be record (BEER and RAISBECK, in press). The record of ${ }^{10} \mathrm{Be}$ is imperfect; evidence for a 2300 year period in the record of this isotope is uncertain at best and generally lacking. This supports the view that the 2300 year radiocarbon line is of terrestrial origin.

The periodicity of ca. 2300 years is also found in the $\delta^{18} \mathrm{O}$ record in ice cores and foraminifera from ocean cores. Glaciation shows this period as does the Middle Europe oak dendroclimatic record and DANSGAARD et al. (1984) report the most prominent period in their Camp Century $\delta^{18} \mathrm{O}$ core to be a line at 2550 years.

Can the source of the 2300 year period be isolated? It appears to be free of modulation by the $\sim 10,000$ year secular trend (denoted by the heavy detrend line in Fig. 1). If the 2300 year source were extraterrestrial, it should interact non-linearly with the secular trend since they are related through $Q \sim B^{-0.52}$ (ELSASSER et al., 1956). No such effect has so far been detected. If the 2300 year period were extraterrestrial, a non-linear mechanism is also required to account for its modulation of the 209 year period. This would not likely be seated in the solar wind which is adiabatic to both periods. Therefore the solar atmosphere becomes a prime candidate. 
On the other hand characteristic deep water residence times for the global oceans range from 1,000 years for the Atlantic to 2,000 years for the full Atlantic-Pacific circulation (BROECKER and LI, 1970). In themselves these times do not explain the global oceanatmosphere resonance required to drive a 2300 year total $\mathrm{CO}_{2}$ cycle, but the times are consistent with such a resonance. YIOU et al. (in press) report periods, primarily Milankovich-derived from deuterium analysis of the Vostok ice core. It is noteworthy that periods at 4.4, 3.5, 2.7, and 2.4 kyears are detected. Their assignment of these is to harmonics arising from orbit-climate interactions. SONETT (1985), SONETT and FINNEY (1990), and DAMON and SONETT (in press) find a 2.3 kyear period in radiocarbon (DAMON and SONETT also report vestigial evidence of an $\sim 4$ kyear period using the Bretthorst algorithm). It may never be possible to isolate the 2.3 kyear forcing with confidence. If due to orbitinsolation it may still drive global $\mathrm{CO}_{2}$ and thus dilution of radiocarbon. If so a search for an ocean-atmosphere resonance independently of orbit- insolation may be meaningless.

\section{Climate and the Partition of Carbon}

The role of the Sun in climate is complicated by the lack of understanding of how correlated bolometric and hydromagnetic mechanisms can coexist on the Sun. Moreover the bolometric component forces modification of the atmospheric $\mathrm{CO}_{2}$ inventory through mediation of the ocean surface temperature and possibly other effects. The Natl. Academy (1975) report settles upon a $2.5^{\circ} \mathrm{C}$ temperature change per doubling of the $\mathrm{CO}_{2}$ atmospheric inventory. Sensitivity studies of temperature vs. $\mathrm{CO}_{2}$ are reported, e.g., by HANSEN et al. (1981) and LAL (1985) and point out the complications arising from sensitivity of the concentration to reservoir content. The atmospheric $\mathrm{CO}_{2}$ inventory and radiocarbon concentration are jointly determined by $\mathrm{CR}$ flux and the terrestrial environment; partitioning of forcing of the net radiocarbon level between atmospheric dilution and CR production is uncertain because both the CR flux and terrestrial reservoir exchange are inconstant. The spectrum exhibits amplitudes of order 2.5 per mil. Using the HOUTERMANS et al. (1973) model for production and reservoir concentration values to establish a qualitative approximation, a 200 year period in production rate results in an attenuation in atmospheric disturbance $\sim 20$ times, depending upon transfer coeflicients. Thus the interplanetary peakpeak variation is very approximately $2.5 \%$. For a steady state (CR addition just equal to decay), the peak-peak radiocarbon variation is due to dilution; the global $\mathrm{CO}_{2}$ variation is $0.5 \%$.

Growth of trees measured by ring width can aid in establishing the thermal chronology for much of the Holocene but is a complicated function of moisture and air temperature. At high altitude tree growth may even be directly dependent upon solar irradiance rather than indirectly through air temperature (FRITTS, 1976). The Campito Mt. record is from the timberline band which progresses and regresses with time. LA MARCHE and MOONEY (1967) find a retreat of about 120-150 meters in timberline altitude from the altithermal till now. LA MARCHE (1973) finds a retreat from $2500 \mathrm{BC}$ till $1700 \mathrm{AD}$ at Sheep Mt. (White Mts.) of about 200 meters suggesting a temperature variation of about $2.1^{\circ} \mathrm{C}$ based on lapse rate. In support of this LA MARCHE (1974) finds a significant correlation between the combined central England (LAMB, 1980) and Northern hemisphere (MITCHELL, 1961) temperature record and White Mt. timberline tree ring width from 800 to $1960 \mathrm{AD} . \Delta T \sim 1.5^{\circ} \mathrm{C}$ vs. $\Delta W \sim 0.5$ $\mathrm{mm}$. The establishment of a true dendrochronological timberline thermometer is still to be made, but changes in the timberline Bristlecone ring growth record support a response 
primarily seated in temperature. LA MARCHE (1974) discussed temperature-moisture stressing upon tree physiology, suggesting that the Campito Mt. Bristlecone pine timberline sequence records primarily thermal stressing. Although the $\Delta^{14} \mathrm{C}$ Maunder peaks (Fig. 2) tend to occur at Bristlecone pine minima detailed correspondence is not always good. The tree response is expected to follow solar irradiance closely while the atmospheric radiocarbon inventory varies approximately as the integrated CR flux which is several decades and is noisy. The radiocarbon record also is likely subject to other forcings which do not correlate with tree growth. But from an average standpoint, as the radiocarbon peaks correspond to solar activity minima, their inverse (solar activity maxima) should correlate positively with tree ring thickness maxima, which is the case. This supports the inference that the trees are responding to aerial temperature rather than to some exotic forcing and that atmospheric temperature is indeed correlated with long period solar activity. Extraction of a time-temperature record for the White Mts. from the tree record is difficult for two reasons: the uncertain physiology of the Bristlecone, their extreme antiquity, and the ever possibility that their growth is stressed by other factors than air temperature. The $\sim 1000$ year "half cycle" in the Bristlecone pine record reported by LA MARCHE (1974) (his Fig. 4) also appears in the analysis of this paper. It corresponds about to the time from the Medieval warm epoch to the present (LAMB, 1980).

\section{Solar Variability}

GoUGH (1988) has reviewed characteristic times for the Sun but no specifically multihundred year periods are identified. It is possible to base global hydromagnetic modes conceptually within a solar context if a core magnetic field of order 1 gauss is admitted. Global solar Alfven wave transit times vary only by about a factor of 10 and estimates are only qualitative but do suggest the possibility of eigenmodes corresponding to periods of perhaps 100-1000 years. However such modes would have to exhibit a significant bolometric connection to account for the combined radiocarbon and Bristlecone variability. It is hardly a hypothesis but the well-known deficit in the high energy solar neutrino flux (See WOLFSBERG and KOCHAROV (in press) for review.) does suggest that understanding of the solar core is still uncertain. Sporadic reports of solar radius variability infer a changes in solar diameter. GILliLAND's (1981) work shows a maximum in solar diameter ca. 1910 corresponding to a minimum in solar activity. Moreover his results show a return to maximum in about 70-80 years suggesting a relation to the Gleissberg period. RIBES et al. (in press) review the field including 18th and 19th century solar observations.

I thank H. C. Fritts and M. K. Hughes for bringing to my attention a number of works on the Bristlecone record, C. R. Stockton for supplying the Campito Mt. Bristlecone record, P. E. Damon for pointing out many nuances in the radiocarbon record, and finally H. E. Suess for originally bringing my attention to the reality and importance of the 200 year line in the radiocarbon spectrum. Some of the work reported here was caried out with support from the NSF solar-terrestrial program.

\section{REFERENCES}

Barton, C. E., R. T. Merrill, and M. BARBetti, Intensity of the earth's magnetic field over the last 10,000 years, Phys. Earth Plan. Int., 20, 96, 1979. 
Beer, J. and G. M. RAISbeck, in The Sun in Time, edited by C. P. Sonett, M. S. Giampapa, and M. S. Matthews, Univ. Arizona press (in press).

Broecker, W. S. and Y.-H. LI, Interchange of water between the major oceans, J. Geophys. Res., 75, 3545-3552, 1970.

BuchtA, V., Influence of the earth's magnetic field on radiocarbon dating, in Radiocarbon variations and absolute chronology, Nobel Symposium, 12, 595, 1970.

CreER, K. M., Geomagnetic field and radiocarbon activity through Holocene time, in NATO Advanced Research Workshop on Secular, Solar, and Geomagnetic variations through the last 10,000 years, edited by F. R. Stephenson and A. W. Wolfendale, NATO ARW series, Kluwer Acad. Publ., 1988.

DAmon, P. E. and C. P. Sonetr, Solar and Terrestrial components of the ${ }^{14} \mathrm{C}$ variation spectrum, in The Sun in Time, edited by C. P. Sonett, M. S. Giampapa, and M. S. Matthews, Univ. Ariz. Press (in press).

Dansgaard, W., S. J. Johnsen, H. B. Clausen, D. Dahl-Jensen, N. Gunderstrup, C. Hammer, and H. OEsChGER, North Atlantic climate oscillations revealed by deep Greenland ice cores, in Climate Processes and Climate Sensitivity, pp. 288-298 AGU Maurice Ewing series, edited by J. E. Hansen and Takahashi, 1984.

ElsASSER, W., E. P. NeY, and J. R. WinCKLER, 1956 Cosmic ray intensity and geomagnetism, Nature, 178, $1226,1956$.

FritTs, H. C., Tree Rings and Climate, Academic Press, 1976.

GILlILAND, R. L., Solar radius variations over the past 265 years, Ap. J., 248, 1144-1155, 1981.

Gleissberg, W., Ascent and descent in the eight year cycle of solar activity, J. Brit. Astron. Assoc., 76, 265-268, 1966.

Gough, D., Theory of solar variation, Il Nuovo Cimento, 90-132, 1988.

Hansen, J., D. Johnson, A. Lacis, S. LebedefF, P. Lee, D. Rind, and G. Russell, Climate impact of increasing atmospheric carbon dioxide, Science, 213, 957-906, 1981.

Houtermans, J. C., H. E. Suess, and H. OeschGer, Reservoir models and production rate variations of natural radiocarbon, J. Geophys. Res., 78, 1897-1908, 1973.

Kromer, B., M. Rhein, M. Bruns, H. Schoch-Fischer, K. O. Münnich, M. Stuiver, and B. Becker, Radiocarbon dating for the 6th to the 8th millennia, Radiocarbon, 28, 954-960, 1986.

LAL, D., The Carbon Cycle and Atmospheric $\mathrm{CO}_{2}$ : Natural Variations Archean to Present, Geophys. Mono. 32, edited by E. T. Sundquist and W. S. Broecker, American Geophys. Union, Washington, D.C., 1985.

LAMB, H. H., The Changing Climate, Methuen, London, 1980.

LA MARChe, V. C. and T. P. HARLAN, Accuracy of tree ring dating of Bristlecone pine for calibration of the radiocarbon time scale, J. Geophys. Res., 78, 8849-8857, 1973.

LA Marche, Jr., V. C., Holocene climatic variations inferred from treeline fluctuations in the White Mts., California, Quaternary Res., 3, 632-660, 1973.

La Marche, V. C. and H. A. Mooney, Altithermal timberline advance in western United States, Nature, 213, 980-982, 1967.

La Marche, V. C., Paleoclimate inferences from long tree-ring records, Science, 183, 1043-1048, 1974.

Linick, T. W., A. Long, P. E. DAMon, and C. W. Ferguson, High-precision radiocarbon dating of Bristlecone pine from 6554 to 5350 BC, Radiocarbon, 28, 943-953, 1986.

Maunder, E. W., The prolonged sunspot minimum, 1645-1715, Brit. Atron. Assoc. J., 32, 140-145, 1922.

McElhinny, M. W. and W. E. Senanyake, Variations in the geomagnetic dipole: the past 50,000 years, Geomag. Geoelect, 34, p. 39, 1982.

Mitchell, J. M., Recent secular changes of global temperature, nn. New York Acad. Sciences, 95, 235250, 1961.

Natl. Acad. of Sciences, Understanding Climate Change, Washington, D.C., 1975.

Pearson, G. W., J. R. Pilcher, M. G. L. Baillie, D. M. Corbett, and F. Qua, High precision ${ }^{14}$ C measurement of Irish oaks to show the natural ${ }^{14} \mathrm{C}$ variations from AD 1840 to $5210 \mathrm{BC}$, Radiocarbon, 28, 911, 1986.

Raisbeck, G. M. and F. YIOU, Cosmogenic ${ }^{10} \mathrm{Be} /{ }^{7} \mathrm{Be}$ as a probe of atmospheric transport processes, Geophys. Res. Lett., 8, 1015-1018, 1981.

Ribes. E., B. Beardsley, T. M. Brown, P. Delache, J. R. Kuhn, F. Leclare, and N. V. Leister, The variability of the solar diameter, in The Sun in Time, edited by C. P. Sonett, M. S. Giampapa, and M. S. Matthews, Univ. Arizona Press (in press). 
SONETT, C. P. and H. E. SUESS, Correlation of bristlecone pine ring widths with atmospheric ${ }^{14} \mathrm{C}$ variations: a climate-Sun relation, Nature, 307, 141, 1985.

SonetT, C. P., Very long solar periods and the radiocarbon record, Rev. Geophys. Spa. Phys., 22, 239254, 1985.

Sonett, C. P. and S. A. Finney, The spectrum of radiocarbon, Phil. Trans. Roy. Soc., A330, 413-426, 1990

Stuiver, M. and P. D. QUAY, Atmospheric ${ }^{14} \mathrm{C}$ changes resulting from fossil fuel $\mathrm{CO}_{2}$ and cosmic ray variability, Earth and Plan. Sci. Lett., 53, 349-362, 1981.

Stuiver, M. and T. F. Braziunes, Atmospheric ${ }^{14} \mathrm{C}$ and century-scale solar oscillations, Nature, 338, 405408, 1989.

SonETT, C. P., The present status of understanding of the spectrum of radiocarbon, Radiocarbon often four decades, in An Interdisciplinary Perspective, edited by R. E. Taylor, A. Long, and R. S. Kra, Springer-Verlag, New York (in press).

SUESS, H. E., The radiocarbon record in tree rings of the last 8000 years, Radiocarbon, 20, 1, 1980 .

Wolfsberg and G. E. Kocharov, in The Sun in Time, edited by C. P. Sonett, M. S. Giampapa, and M. S. Matthews, Univ. Arizona Press (in press).

Yiou, P., C. Genthon, J. Jouozel, M. Ghil, H. Le Treut, J. M. Barnola, C. Lorius, and Y. N. KoRotkevitch, High-frequency paleovariability in climate and in $\mathrm{CO}_{2}$ levels from Vostok ice-core records, in Interaction of the Global Carbon and Climatic Systems, edited by R. Keir, Electr, Power Res. Inst. (in press). 